\title{
Viabilidade do uso de escória em camadas de pavimentos flexíveis: análise bibliográfica
}

O pavimento do tipo flexível é composto por diferentes camadas as quais possuem espessuras distintas. O material que compõe cada camada varia conforme fatores de ordem econômica, técnica, disponibilidade de materiais, entre outros. A maioria dos pavimentos são compostos por materiais tradicionais, como, por exemplo: os granulares (solo, pedregulho, cascalho, pedra britada, etc.); e os estabilizantes (cal, cimento, betumes etc.). Entretanto, é cada vez mais frequente pesquisas que estudam materiais que possam substituir os convencionais. Exemplo de material convencional é a escória de aciaria, subproduto do aço, que pode ser utilizada na composição de certas camadas do pavimento flexível. Nesta pesquisa analisou-se o uso de escória de aciaria em camadas de base e sub-base, levando em conta principalmente a resistência das misturas e seu potencial expansivo, com base no panorama nacional de pesquisas que abordam o uso de escória de aciaria como material alternativo aos convencionais, visando sua utilização em camadas de base e sub-base do pavimento. Muitos trabalhos analisados constataram a viabilidade do emprego da escória de aciaria em camadas de pavimentos. O referido resíduo, para uma mesma dosagem, a depender de seu processo de fabricação e o tipo de solo utilizado pode apresentar resultados diversos; todavia, a essas misturas podem ser adicionados outros materiais a fim de melhorar a resistência, como, por exemplo, a cal. Dos trabalhos analisados os que mais se destacaram foram o P1, P4, P5, P6, P7 e P8 visto que apresentaram resultados satisfatórios de CBR e expansão. Em contrapartida trabalhos como o P2 e P3 não apresentaram resultados aceitáveis.

Palavras-chave: Pavimentação; Material alternativo; Ensaios laboratoriais.

\section{Feasibility of the use of slag in flexible floor layers: bibliographic analysis}

\begin{abstract}
The flexible sidewalk is composed of different layers that have different thicknesses. The material that makes up each layer varies according to economic and technical factors, availability of materials, among others. Most sidewalks are composed of traditional materials, such as granular (soil, gravel, crushed stone, etc.) and stabilizers (lime, cement, bitumen, etc.). However, research is increasingly common to study materials that can replace conventional ones. An example of a conventional material is steel slag, a steel by-product, which can be used in the composition of certain layers of flexible sidewalk. This research analyzed the use of steel slag in base and sub-base layers, taking into account mainly the mixture strength and its expansive potential, based on the national research landscape that addresses the use of steel slag as an alternative material to conventional materials, aiming its use in base and sub-base layers of sidewalk. Many studies have found the feasibility of using steel slag in sidewalk layers. This waste, for the same dosage, depending on its manufacturing process and the type of soil used can present different results; however, other materials can be added to these mixtures in order to improve resistance, such as, for example, lime. Of the works analyzed, the ones that stood out the most were P1, P4, P5, P6, P7 and P8, since they showed satisfactory results for CBR and expansion. On the other hand, works such as $\mathrm{P} 2$ and P3 did not present acceptable results.
\end{abstract}

Keywords: Paving; Alternative material; Laboratory tests.

Topic: Ensinos Multidisciplinares

Reviewed anonymously in the process of blind peer.
Received: 05/06/2021

Approved: 26/06/2021
Larissa Macário da Silva

Instituto Tocantinense Presidente Antônio Carlos, Brasil http://lattes.cnpq.br/4053474280236075

larissamacario184@gmail.com

Rafaella Oliveira Guimarães Santos

Instituto Tocantinense Presidente Antônio Carlos, Brasil http://lattes.cnpq.br/2006870316534982

rafaellaguimaraes.eng@gmail.com

Marcos Vinicius Dias da Silva

Instituto Tocantinense Presidente Antônio Carlos, Brasil http://lattes.cnpq.br/6838925859227163

viniciusmarcosdias12@gmail.com

\section{Referencing this:}

SILVA, L. M.; GUIMARÃES, R. O.; SILVA, M. V. D.. Viabilidade do uso de escória em camadas de pavimentos flexíveis: análise bibliográfica. Revista Ibero Americana de Ciências Ambientais, v.12, n.6, p.681690, 2021. DOI: http://doi.org/10.6008/CBPC2179$\underline{6858.2021 .006 .0056}$ 


\section{INTRODUÇÃO}

Os pavimentos flexíveis são estruturas constituídas de várias camadas de espessuras variáveis e diversos materiais. Geralmente, as camadas que constituem o pavimento flexível são compostas de materiais granulares (solo, pedregulho, cascalho, pedra britada etc.) podendo ser acrescidos de um material estabilizante (cal, cimento, betumes etc.) para melhorar suas propriedades físicas. Os pavimentos mais simples são constituídos de base e revestimento. Mas podem ainda constituir-se de outras como a regularização e reforço do subleito e a sub-base, conforme necessidade. A definição da composição e da espessura de cada camada que irá constituir o pavimento é estabelecida no dimensionamento do mesmo (MARQUES, 2009).

A granulometria dos agregados é uma das propriedades mais importantes tendo em vista que afeta a rigidez, a estabilidade, a durabilidade, a permeabilidade, a trabalhabilidade e a resistência à fadiga, entre outros aspectos da mistura. Os agregados de diversas fontes são constituintes dos pavimentos em várias camadas, e tem função de contribuir na estabilidade mecânica, suportando as tensões impostas na superfície e no interior do pavimento (BERNUCCl et al., 2008).

O crescimento populacional aliado ao desenvolvimento industrial acarreta uma grande produção de produtos e insumos, gerando aumento do consumo de recursos naturais não renováveis e grande quantidade de resíduos sólidos pelas indústrias, podendo suscitar impactos ambientais negativos. Além do acréscimo na quantidade, os resíduos sólidos podem abrigar em sua composição elementos sintéticos e perigosos aos ecossistemas e à saúde humana, promovendo aumento da poluição da água, do ar e do solo, caso sua destinação e/ou disposição final não ocorra de forma adequada (COSTA, 2010).

A produção acumulada do Brasil em janeiro e fevereiro deste ano foi de 5,8 milhões de toneladas, o que significa um aumento de 7,3\% em relação ao mesmo período de 2020. Em dois meses, as vendas internas de laminados atingiram 37 milhões de toneladas, $24 \%$ acima do preço de mercado no mesmo período de 2020. O consumo aparente é de 4,3 milhões de toneladas, um aumento de $25 \%$ em relação a janeiro de 2020 e fevereiro de 2020.

Dentro deste enfoque, ocorre a possibilidade de estudar se a escória oriunda dos fornos à indução reúne as propriedades que a torna possível de ser utilizada como agregado na composição do pavimento, dando-lhe assim, uma destinação final, com possibilidade de redução de custo para as empresas fundidoras, que devem dar uma destinação adequada ao material, com possível redução do volume depositado em aterro.

A presente pesquisa teve como objetivo analisar o panorama nacional de pesquisas que abordaram o uso de escória de aciaria como material alternativo aos convencionais, visando sua utilização em camadas de base e sub-base do pavimento.

\section{METODOLOGIA}

A pesquisa foi desenvolvida de forma exploratória, buscando embasamento teórico em publicações 
de artigos, dissertações e teses relacionados ao uso de escória de aciaria em camadas do pavimento. 0 método exploratório é visto como importante no tratamento de termos que são relevantes para a sociedade e por se tratar de uma temática pouco estudada (GIL, 2008). Quanto aos procedimentos, os dados foram obtidos de documentos publicados, sendo definida como bibliográfica e documental (FACHIN, 2003), permitindo que as obras pesquisadas possam ser comparadas e os seus dados mensurados.

O processo de busca foi realizado no período de setembro de 2020 a janeiro de 2021, e envolveu as plataformas Scielo, Periódicos Capes e Google Acadêmico. Optou-se ainda por buscar publicações do período de 2010 a 2020. Como etapa inicial, para as buscas, utilizaram-se as palavras-chave escória, slag, pavimento e paving, além de filtrar a busca para trabalhos publicados no período de interesse mencionado. As palavraschave foram usadas sozinhas e em combinações. Outro item observado para exclusão inicial de artigos foi o local da pesquisa, uma vez que se busca o panorama nacional do uso de escória de aciaria, ou seja, pesquisas desenvolvidas no Brasil.

Na plataforma Scielo, inicialmente foi possível observar 185 publicações nos anos de 2010 a 2020 ao se utilizar apenas o termo 'escória'. Observou-se inúmeras publicações que envolviam o uso de escória em outras temáticas, como em dosagens de concreto, correção de acidez do solo, produção de geopolímeros e outras. Dos 185 artigos, pesquisas realizadas no Brasil foram 71. Após leitura dos títulos, chegou-se a 2 artigos potenciais. Usando o mesmo período de publicação e os termos 'escória' e 'paving', chegou-se a 3 publicações, que já englobavam os 2 potenciais anteriores. Após a etapa seguinte de leitura dos títulos e resumos, dois artigos estavam alinhados com a temática da pesquisa. Por fim, ainda usando o Scielo, com as palavras 'slag' e 'paving', chegou-se a 3 artigos, que foram reduzidos aos mesmos já selecionados anteriormente após leitura dos títulos e resumos.

Utilizando-se a plataforma Periódicos Capes, obteve-se 938 publicações que envolviam o termo 'escória'. O número de publicações caiu para 642 quando se verificou o período de publicação entre 2010 e 2020. Buscando por 'escória de aciaria', foram 62 resultados, de 2010 a 2020. Novamente, correção da acidez do solo e produção de cimento e/ou concretos foram algumas das temáticas observadas nas publicações. Pode-se ressaltar ainda os inúmeros artigos relacionados ao uso de escória em misturas asfálticas, tanto nacionais quanto internacionais. Tais trabalhos não foram selecionados por buscarem-se pesquisas que envolvem o uso de escória nas camadas de base e sub-base de pavimentos. Com as palavras de busca 'slag' e 'paving', obteve-se 1978 artigos. Destes, excluiu-se os que discorriam sobre cimento e misturas asfálticas, alcançando o número de 83 artigos. Após leitura dos títulos e resumos das pesquisas realizadas no Periódico Capes, pode-se contar com 6 artigos relacionados à temática proposta.

Considerando a pesquisa realizada nas plataformas Scielo e Periódicos Capes, obteve-se no total 8 artigos coerentes com a temática proposta, que tratam do uso de escória em camadas do pavimento. Buscando-se um número maior de pesquisas sobre o assunto, optou-se por incorporar a base de dados no Google Acadêmico, sendo possível abordar publicações de periódicos não disponíveis nas plataformas citadas e incluindo ainda pesquisas publicadas em outros formatos como trabalhos de conclusão de curso, dissertações, teses e publicações em eventos. 
O Google Acadêmico conta com filtros de pesquisa mais restritos. Inicialmente, utilizando-se a palavra 'escória' obteve-se 15600 resultados entre os anos de 2010 e 2020. Mantendo o período de publicação e as palavras 'escória' e 'pavimento', 6400 publicações. Utilizaram-se mais termos associados à temática da pesquisa, como base e sub-base, diminuindo o número de publicações para 1410. Após leitura dos títulos, os que se tratavam de escória de aciaria foram 256 publicações. Mediante a próxima etapa da leitura dos resumos para seleção dos trabalhos que abordam o uso da escória de aciaria em camadas de base e sub-base de pavimentos, contando nesta etapa com 14 publicações, em que alguns desses já constam na base de busca dos artigos analisados, onde apenas 8 atenderam aos critérios, esses foram selecionados com base no Google Acadêmico e as demais plataformas, conforme descritos na Tabela 1.

Tabela 1: Artigos Selecionados.

\begin{tabular}{llll}
\hline ID & Título & Ano & Autores \\
\hline P1 & $\begin{array}{l}\text { Avaliação do comportamento geotécnico de um solo laterítico estabilizado com cal e rejeito de } \\
\text { flotação de minério de ferro }\end{array}$ & 2019 & GRASSE et al. \\
\hline P2 & $\begin{array}{l}\text { Caracterização de misturas de rejeitos de minério de ferro melhoradas com adição de cimento com } \\
\text { vistas à aplicação em estradas e aterros }\end{array}$ & 2013 & OLIVEIRA, T. M. \\
\hline P3 & $\begin{array}{l}\text { Caracterização do Comportamento Mecânico de Misturas de Solo-Escória de Aciaria-Cinza Volante } \\
\text { Visando a Aplicação em Pavimentação. }\end{array}$ & 2018 & $\begin{array}{l}\text { SANTOS et } \\
\text { (2018) }\end{array}$ \\
\hline P4 & Estudo de Estabilização Granulométrica de Solos Utilizando Rejeito de Mineração & 2018 & RODRIGUES \\
\hline P5 & $\begin{array}{l}\text { Estudo do comportamento mecânico de misturas de solo e escória de aciaria para aplicação na } \\
\text { construção rodoviária na região metropolitana de Fortaleza }\end{array}$ & 2015 & PARENTE et al. \\
\hline P6 & Laboratory and field evaluation of KR slag-stabilized soil for paving applications & 2019 & PIRES et al. \\
\hline P7 & Revisão de estudos sobre a aplicação de escória de aciaria na pavimentação rodoviária & 2015 & $\begin{array}{l}\text { PINHEIRO } \\
\text { et al. }\end{array}$ \\
\hline P8 & $\begin{array}{l}\text { Ntilização da escória de aciaria em combinação com solo para uso em camadas de pavimentação } \\
\text { rodoviária }\end{array}$ & 2020 & COSTA et al. \\
\hline
\end{tabular}

Vale ressaltar que a utilização de escória de aciaria não fica restrita à pavimentação, há trabalhos que mostram que seu uso é adequado para outras finalidades. No processo de busca realizado observaram-se pesquisas que envolviam a utilização do resíduo para outros fins, como a confecção de blocos cimentícios de implantação de pavimentos intertravados, correção do solo em plantações de produtos agrícolas e misturas asfálticas. Tais trabalhos não foram selecionados por não estarem alinhados com o tema da presente pesquisa.

\section{DISCUSSÃO TEÓRICA}

Com base nos artigos citados na Tabela 1 nota-se que, no Brasil, poucos trabalhos foram desenvolvidos com o intuito de se constatar a viabilidade do uso de escória de aciaria na composição de base e sub-base de pavimentos asfálticos (levando-se em conta a realização de ensaios de caracterização geotécnica e para verificar o comportamento mecânico dos materiais). O Gráfico 1, construído a partir da Tabela 1, relaciona os artigos publicados ao longo dos anos. Pode-se verificar que entre os anos de 2010 e 2020, foram encontrados 8 trabalhos que vão ao encontro do objetivo deste projeto e destes, o ano que registrou o número maior de publicações foi em 2019. 


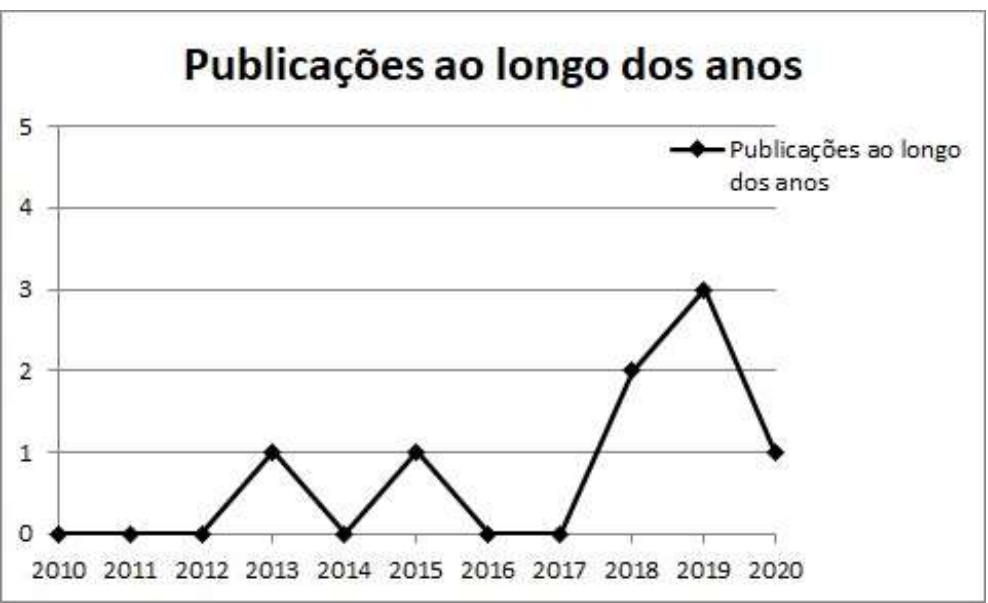

Gráfico 1: Publicações ao longo dos anos.

Buscando-se justificar o maior número de publicações nos anos de 2018 e 2019, pesquisou-se por episódios acontecidos à época. Neste sentido, os rompimentos de barragens de rejeitos que foram vistos como grandes tragédias foram averiguadas. No ano de 2015, no município de Mariana (MG), a barragem de Fundão, pertencente a Mineradora Samarco que é controlada pela Vale S.A. e BHP Billiton, rompeu matando 19 pessoas e causando um desastre incalculável ao meio ambiente. A barragem abrigava cerca de 56,6 milhões de $\mathrm{m}^{3}$ de lama de rejeito; cerca de 43,7 milhões de $\mathrm{m}^{3}$ vazaram atingindo uma grande área o que causou grande destruição no entorno. Em 25 de janeiro de 2019 ocorreu o maior desastre ambiental envolvendo barragens da história do Brasil: rompimento da barragem da Vale em Brumadinho (MG). A tragédia matou 259 pessoas e deixou 11 desaparecidas (ANA, 2019; ANTUNES et al., 2019).

Desse modo, pode-se inferir que os rompimentos de barragens de rejeitos que foram vistos como grandes tragédias despertaram maior interesse em pesquisadores a respeito do reaproveitamento de resíduos da exploração de minérios, relacionando-se a quantidade maior de trabalhos publicada no ano de 2018 e 2019.

Além dos rompimentos comentados, a Lei 14.066 entrou em vigor em 2020, quando passou-se a ter uma nova Política Nacional de Segurança das Barragens (PNSB) no Brasil. A norma surgiu do PL 550/2019 apresentada pela senadora Leila Barros (PSB-DF) motivada pelo rompimento da barragem em Brumadinho (MG) e sancionada pelo presidente Jair Bolsonaro. Entre outras medidas, a nova lei proíbe a construção de barragens do tipo 'a montante' como era o caso das usadas em Brumadinho e Mariana.

\section{Resultados de CBR, expansão e suas aplicabilidades}

O método de dimensionamento de pavimentos empírico utilizado pelo DNIT tem como base parâmetros de expansão e Índice de Suporte Califórnia (ISC), popularmente conhecido por CBR, de Califórnia Bearing Ratio. De acordo com o DNIT (BRASIL, 2006), as amostras para serem utilizadas nas camadas da pavimentação deverão conter os parâmetros especificados: Material para execução de reforço de subleito: $C B R \geq 12 \%$, expansão $\leq 1,0 \%$; Material para execução de sub-base: $C B R \geq 20 \%$, expansão $\leq 1,0 \%$; Material para execução de base de pavimento: $C B R \geq 80 \%$, expansão $\leq 0,5 \%$ e para caso de rodovias vicinais $C B R \geq$ $60 \%$, expansão $\leq 0,5 \%$. 
A Tabela 2 demonstra os resultados obtidos em ensaios de expansão e CBR nos trabalhos abordados na presente pesquisa. Os artigos abordaram diferentes dosagens envolvendo escória e na maioria das vezes solo regional. Algumas dosagens contaram também com aditivos como cal e cinza volante. A Tabela 2 apresenta ainda a aplicabilidade de tais misturas em camadas do pavimento, conforme parâmetros de DNIT (BRASIL, 2006).

Tabela 2: Resultados de expansão, CBR e aplicabilidade em camadas de pavimento.

\begin{tabular}{|c|c|c|c|c|}
\hline ID & Dosagens & CBR (\%) & Expansão (\%) & Aplicabilidade \\
\hline \multirow{3}{*}{ P1 } & $49 \%$ solo $+2 \%$ cal + 49\% & 80 & - & Base e Sub-base \\
\hline & $48 \%$ solo + 4\%cal + 48\%escória & 105 & - & Base e Sub-base \\
\hline & $47 \%$ solo + $6 \%$ cal + $47 \%$ escória & 115 & - & Base e Sub-base \\
\hline \multirow{4}{*}{ P2 } & 30\%escória + 70\% escória (concentração) & 20,4 & 0 & Sub-base \\
\hline & 40\%escória (flotação) + 60\% escória (concentração) & 17 & 0 & Reforço de subleito \\
\hline & 50\% escória + 50\% escória (concentração) & 16 & 0 & Reforço de subleito \\
\hline & $60 \%$ escória $+40 \%$ escória (concentração) & 15,7 & 0 & Reforço de subleito \\
\hline \multirow{3}{*}{ P3 } & $87,5 \%$ escória $+12,5 \%$ cinza volante & 14,8 & 1,83 & Reforço de subleito \\
\hline & $100 \%$ escória $+0 \%$ cinza volante & 21,2 & 2,23 & Reforço de subleito e sub-base \\
\hline & $75 \%$ escória $+25 \%$ cinza volante & 29,1 & 1,5 & Reforço de subleito e sub-base \\
\hline \multirow{3}{*}{ P4 } & $90 \%$ solo + 10\%escória & 33,5 & 0,25 & Reforço de subleito e sub-base \\
\hline & $80 \%$ solo + $20 \%$ escória & 44,5 & 0,15 & Reforço de subleito e sub-base \\
\hline & $70 \%$ solo + 30\%escória & 18 & 0,09 & Reforço de subleito \\
\hline \multirow{2}{*}{ P5 } & $50 \%$ solo + 50\%escória & 50 & 0 & Sub-base \\
\hline & $30 \%$ solo + 70\%escória & 70 & 0 & Base \\
\hline \multirow{3}{*}{ P6 } & $80 \%$ solo + 20\%escória & 132 & 0,01 & Base e Sub-base \\
\hline & $75 \%$ solo + 25\%escória & 69,5 & 0 & Base e Sub-base \\
\hline & $85 \%$ solo + $15 \%$ escória & 47,8 & 0 & Base e Sub-base \\
\hline \multirow{3}{*}{ P7 } & $30 \%$ solo + 70\%escória & 50 & 0 & Sub-base \\
\hline & $50 \%$ solo + 50\%escória & 70 & 0 & Base \\
\hline & 100\%escória & 0 & 0,34 & Não aplicável/resultados insatisfatórios \\
\hline \multirow{2}{*}{ P8 } & $85 \%$ solo + 15\%escória & 21,3 & 0,0051 & Reforço de subleito e sub-base \\
\hline & $70 \%$ solo + 30\%escória & 22,4 & 0 & Reforço de subleito e sub-base \\
\hline
\end{tabular}

Pode-se notar que nem sempre uma determinada mistura (dosagem) é adequada para as diferentes camadas. A que é adequada para compor a camada de reforço de subleito ou sub-base não é, necessariamente, adequada para a base.

Conforme os dados apresentados na Tabela 2 nota-se que diferentes misturas foram formadas com os materiais escória de aciaria e solo (conquanto em algumas delas encontrou-se a presença de outros materiais como a cal e a cinza volante). Em vários trabalhos é possível constatar a viabilidade do uso das misturas visto que apresentaram resultados de CBR satisfatórios; porém, observa-se uma grande variação nos resultados apresentados. Isso provavelmente se justifica devido ao fato de que, nos trabalhos, as escórias utilizadas tinham naturezas distintas (processamento) e os solos também possuíam propriedades diferentes.

Segundo Machado (2000), os três grandes processos de fabricação do aço são divididos conforme processo de refino: LD (Linz-Donawitz) ou BOF (BlastOxygenFurnace), este utiliza o conversor a oxigênio; Elétrico ou EAF (Eletric ArcFurnace), utiliza o forno de arco elétrico; OH (Open Heart), que utiliza o forno Siemens-Martin. No processo de beneficiamento do aço são gerados diversos rejeitos siderúrgicos, entre eles destacam-se: a escória de alto-forno, o pó de alto-forno, a lama de alto-forno, a escória de dessulfuração, a escória de aciaria LD, a lama grossa de aciaria, a lama fina de aciaria e a carepa (GEYER, 2001).

A depender do processo de fabricação do aço a escória de aciaria recebe diferentes denominações. 
Assim, tem-se: escória oxidante, origina-se das reações de oxidação dos elementos de carbono, fósforo e silício, resultado da injeção de oxigênio no aço fundido (refino oxidante), ela é formada nos processos LD, EAF e OH (SANTOS, 2013); escória redutora, originado do vazamento da escória oxidada, aqui, adiciona-se elementos de liga junto com o Óxido de cálcio $(\mathrm{CaO})$ e a fluorita ( $\mathrm{CaF} 2)$, afim de promover a dessulfuração do aço fundido (FREITAS, 2007).

De acordo com Santos (2013), de maneira geral, há dois tipos de escórias siderúrgicas produzidos em grandes quantidades: escória de alto-forno, produto que tem origem da fusão redutora dos minérios na produção do ferro gusa, como se percebe, ela é obtida diretamente do alto forno, geralmente com excesso de teor de carbono e muitas impurezas; escórias de aciaria, origina-se da produção do aço, obtida em fornos elétricos e conversores de oxigênio, no período de conversão de sucata em aço, elas podem ser oxidantes ou redutoras. Logo, como se pode ver, a depender do processo de fabricação as propriedades da escória variam bastante, o que pode interferir de forma decisiva nos parâmetros que medem a resistência das misturas.

É o que ocorre, por exemplo, com a mistura 2 do trabalho P4 e a mistura 1 do trabalho P6 em que foi adotada a mesma dosagem ( $80 \%$ solo $+20 \%$ escória), porém, os resultados foram diferentes. Isso mostra que não só a dosagem interfere nos resultados, as propriedades dos materiais constituintes das misturas também. A natureza da escória de aciaria era divergente; isso, combinado com o tipo de solo, que também era distinto, pode ter contribuído para a obtenção de resultados tão diversos.

Além das diferentes escórias, os solos foram coletados em locais distintos, sendo que no P4 era solo vermelho com característica argilosa, do estado de Minas Gerais (não foi especificado o processo de beneficiamento da escória); no P6, o solo também era argiloso, do estado do Espírito Santo, e utilizou-se escória de aço de dessulfuração do processo do Reator Kambara (escória KR). Nos casos comentados, o melhor resultado foi o da mistura da escória KR com o solo argiloso, que obteve CBR 132\% e expansão 0,01\%, apresentando aplicabilidade em camadas de base de pavimento. Situação semelhante ocorreu com os trabalhos P5 e P6. Todos esses tiveram como material alternativo a escória de aciaria, diversificando somente no P6, este utilizou um material diferente dos demais.

Os resultados encontrados pelo trabalho P3, que utilizou cinza volante nas dosagens, chamaram a atenção. No que diz respeito aos valores de CBR as misturas possuem aplicabilidade em sub-base e reforço de subleito; entretanto, os valores de expansão foram insatisfatórios (excessivos). Vale ressaltar que a expansão da escória foi reduzida com a adição de cinza volante, entretanto, não o suficiente para viabilizar o uso em camadas de pavimento.

Quando se considera a dosagem com $100 \%$ de escória oxidante de aciaria elétrica, obteve-se a maior expansão $(2,23 \%)$ e quando se admitiu a menor proporção $(75 \%)$, o valor da expansão obtido foi o menor $(1,5 \%)$. Provavelmente a natureza da escória de aciaria e/ou o solo utilizado influenciaram nos resultados.

Comparando os trabalhos P1, P5 e P7 observou-se que todos utilizaram a mesma dosagem, de aproximadamente $50 \%$ solo $+50 \%$ escória, contudo, os resultados de CBR foram diferentes. O trabalho com melhor desempenho foi o P1 visto que obteve maiores valores de resistência. Esse resultado satisfatório pode ser justificado devido ao fato de apenas nele haver adição de cal nas misturas. Assim, o CRB para este 
trabalho variou de $80 \%$ a $115 \%$. Já nos outros, sem adição de cal, o CBR oscilou de 50\% a $70 \%$.

Os trabalhos que apresentaram melhores resultados foram o P1, P5, P6 e P7. Os valores de CBR encontrados variaram de 47,8\% a 132\%; já a expansão não ultrapassou 0,34\%. Já os demais trabalhos obtiveram valores de CBR relativamente baixos, de 14,8\% a 44,5\%; e em alguns a expansão foi excessiva (chegou a 2,23\%). As dosagens mais comuns adotadas foram 30\%solo + 70\%escória, 50\%solo + 50\%escória, $75 \%$ solo $+25 \%$ escória, $80 \%$ solo +20 escória, $85 \%$ solo $+15 \%$ escória, $100 \%$ escória. As dosagens menos utilizadas foram: 60\%escória + 40\%escória (concentração), 90\%solo + 10\%escória.

\section{Ensaios realizados}

A Tabela 3 apresenta os ensaios identificados em cada um dos trabalhos.

Tabela 3: Ensaios realizados nos trabalhos $\mathrm{P} 1$ a $\mathrm{P} 8$.

\begin{tabular}{|c|c|c|c|c|c|c|c|c|c|}
\hline Artigo & & P1 & $\mathbf{P 2}$ & P3 & P4 & P5 & P6 & P7 & P8 \\
\hline \multirow{10}{*}{ Ensaios } & Análise granulométrica & $x$ & $x$ & $x$ & $\mathrm{x}$ & & & $x$ & $x$ \\
\hline & Limites de Atterberg & $x$ & $x$ & $x$ & $x$ & & $x$ & $x$ & $x$ \\
\hline & Massa específica dos grãos & $x$ & $x$ & $x$ & $x$ & & $x$ & $x$ & $x$ \\
\hline & Compactação & $x$ & $\mathrm{x}$ & $\mathrm{x}$ & $\mathrm{x}$ & & $x$ & $x$ & $\mathrm{x}$ \\
\hline & Expansão & & $x$ & $x$ & $\mathrm{x}$ & $x$ & $x$ & $x$ & $\mathrm{x}$ \\
\hline & CBR & $\mathrm{x}$ & $\mathrm{x}$ & $x$ & $x$ & $x$ & $x$ & $\mathrm{x}$ & $\mathrm{x}$ \\
\hline & Abrasão Los Angeles & & & & & $x$ & $x$ & & \\
\hline & Resistência a compressão simples & & $x$ & $x$ & $x$ & & $x$ & & \\
\hline & Permeabilidade & & $\mathrm{x}$ & $x$ & & & & & \\
\hline & Equivalência de areia & $x$ & & & & & & & \\
\hline
\end{tabular}

Pode-se observar que o trabalho que apresentou menos informações com as quais é possível verificar a viabilidade do uso do material alternativo na pavimentação foi o P5.

Grande parte dos trabalhos (75\%) realizou os ensaios de caracterização granulométrica a fim de melhor conhecer o solo; $87,5 \%$ realizaram os ensaios de limites de consistência, massa específica dos grãos e compactação. Em relação aos parâmetros que medem a resistência do solo, tem-se as seguintes porcentagens: $100 \%$ apresentaram valores de CBR e em 75\% contém os valores de expansão. Resistência a compressão simples foi realizado por $50 \%$ dos trabalhos; os outros ensaios mencionados na tabela foram realizados por menos de $30 \%$ dos trabalhos. Dos trabalhos pesquisados $50 \%$ indicam que a escória possui viabilidade técnica para ser empregada em camadas de sub-base e base de pavimento.

Nas análises efetuadas verificou-se a inexistência dos dados de ensaio para determinação do módulo de resiliência dos solos utilizando o equipamento triaxial de carga repetida, os resultados obtidos por esse ensaio podem ser empregados para a determinação dos valores de módulo elástico a diferentes níveis de tensões ou para método de modelos elásticos não lineares usados na análise numérica de dimensionamento de pavimentos. O módulo elástico é a propriedade mecânica do solo, indispensável para a análise das estruturas dos pavimentos quanto as tensões e deformações.

\section{CONCLUSÕES}

Não obstante o número de trabalhos que estão totalmente alinhados com esta pesquisa e que foram publicados entre os anos de 2010 e 2020 tenha sido relativamente baixo, os resultados das análises obtidas 
no levantamento bibliográfico foram satisfatórios, visto que comprovaram que certas misturas de solo com escória (às vezes com adição de outros materiais) são viáveis tecnicamente para serem aplicadas em camadas de base e sub-base de pavimentos flexíveis. Sendo assim, o objetivo geral da pesquisa foi atingido, isto é, verificou-se o panorama nacional de pesquisas que abordaram o uso de escória de aciaria como material alternativo aos convencionais.

Os trabalhos P2 e P3 obtiveram aplicabilidade insatisfatória, ambos com baixos valores de CBR e o P3 com elevados resultados de expansão. Os demais trabalhos (P1, P4, P5, P6, P7 e P8) obtiveram viabilidade de utilização das dosagens propostas em camadas de pavimento no que diz respeito aos parâmetros de CBR e expansão. Destes, os que se destacam são P1 e P6; embora P1 não tenham apresentado resultados de expansão, nota-se que à medida que o teor de cal na mistura solo/escória é elevado os resultados de CBR aumentam, chegando a $115 \%$ na dosagem onde foi acrescido o maior teor de cal $447 \%$ solo $+6 \%$ cal + 47\%escória); em P6 observa-se também resultados satisfatórios, sendo que a melhor dosagem encontrada foi $80 \%$ solo $+20 \%$ escória, com resultado de CBR de $132 \%$ e em todas as misturas os resultados de expansão foram adequados (não ultrapassando 0,01\%).

No que diz respeito ao uso de aditivos, ao se adicionar cal em P1 as misturas tiveram aumento nos resultados de CBR. A adição de cinza volante se mostrou interessante para redução da expansão da escória em P3.

Quanto aos ensaios realizados, pode-se inferir que os ensaios de caracterização, compactação, expansão e CBR são unanimidade entre as pesquisas. Conhecer o material com que se trabalha através destes ensaios é, e deve continuar sendo, primordial para verificação de viabilidade de seu uso em pavimentação e outras áreas.

Conclui-se que por meio deste são notório a viabilidade e a importância da utilização da escória de aciaria na pavimentação, pois a mesma apresentou resultados satisfatórios para implantação na camada de base, sub-base e reforço do subleito, bem como a contribuição para com o meio ambiente. Vale destacar ainda que as possibilidades são infinitas de utilização da escoria de aciaria no Brasil, pois é um dos países que se destaca no que diz respeito a geração deste resíduo.

Sugere-se para trabalhos futuros que buscam a viabilidade do uso de escória em camadas de pavimento, a realização do ensaio de módulo de resiliência, uma vez que este contribui para o dimensionamento com a nova ferramenta que está em uso pelo Departamento Nacional de Infraestrutura de Transportes - DNIT, batizado como o Novo Método de Dimensionamento Nacional - Método Medina, desenvolvido com o intuito de aumentar a segurança e confiabilidade nos projetos das vias e redução dos custos com as manutenções. O método, que é mecanístico-empírico, permite a utilização de materiais das mais diversas categorias, possibilitando o uso dos recursos da localidade por exemplo. Pode-se ainda propor diferentes dosagens como $60 \%$ solo $+40 \%$ escória, $46 \%$ solo $+8 \%$ cal $+46 \%$ escória, $45 \%$ solo $+10 \%$ cal + 45\%escória e $70 \%$ escória + 30\%cinza volante. A adição de cinza volante melhora as misturas que apresentam alta expansão e a adição de cal, o CBR. 


\section{REFERÊNCIAS}

ANA. Agência Nacional de Águas. Especialistas discutem e informam sobre a evolução da qualidade das águas do rio Paraopeba e de Três Marias desde o rompimento da barragem em Brumadinho. ANA, 2019.

ANTUNES, N. M.; OLIVEIRA, E. A.; RAMOS, P. M.. Acidente de trabalho ampliado: o rompimento da barragem de Fundão nos jornais impressos do Espírito Santo. Revista Brasileira de Saúde Ocupacional, v.45, 2019. DOI: http://doi.org/10.1590/2317-6369000013719

BERNUCCl, L. B.. Pavimentação asfáltica: Formação básica para engenheiros. 3 ed. Rio de Janeiro: Trama Criações de Arte, 2008.

BRASIL. Departamento Nacional de Infraestrutura de Transportes. Manual de Pavimentação. DNIT - IPR 719: Dimensionamento de Pavimentos Flexíveis. 3 ed. Rio de Janeiro: DNIT, 2006.

BRASIL. Decreto Lei $\mathbf{n} . \mathbf{1 4 . 0 6 6}$, de $\mathbf{3 0}$ de setembro de 2020. Altera o regramento aplicável a segurança de barragens. Lex: coletânea de legislação: edição federal, São Paulo, Seção 1. Brasília: DOU, 2020.

COSTA, J. G. S.. Aspectos técnicos da utilização da lama de aciaria em processo siderúrgico, tratada por processo de sinterização. Monografia (Especialização em Gestão Ambiental) - Centro Universitário do Leste de Minas, Coronel Fabriciano, 2010.

COSTA, S. N.; SANTOS, R. O. G.. Utilização da escória de aciaria em combinação com solo para uso em camadas de pavimentação rodoviária. Revista Engineering Sciences, v.8, n.1, p.57-66, 2020. DOI: http://doi.org/10.6008/CBPC2318$\underline{3055.2020 .001 .0007}$

FACHIN, O.. Fundamentos de metodologia. 4 ed. São Paulo: Saraiva, 2003.

FREITAS, H. B.. Misturas Asfálticas de Módulo Elevado com Uso de Escória de Aciaria com Agregado. Dissertação (Mestrado em Ciências em Engenharia Civil) - Universidade Federal do Rio de Janeiro, Rio de Janeiro, 2007.

GEYER, R. M. T.. Estudo sobre a potencialidade de uso das escórias de aciaria como adição ao concreto. Tese (Doutorado em Engenharia) - Universidade Federal do Rio Grande do Sul, Porto Alegre, 2001.

GRASSE, B. P.; SONCIM, S. P.; ALMEIDA, M. O.; OLIVEIRA, C. A. S.; BELOTTI, F. M.; CAVALCANTE, E. H.; RESENDE, L.. Avaliação do comportamento geotécnico de um solo laterítico estabilizado com cal e rejeito de flotação de minério de ferro. In: CONGRESSO DE PESQUISA E ENSINO EM TRANSPORTE DA ANPET, 33. Anais. Balneário Camboriú,
2019.

MACHADO, A. T.. Estudo Comparativo dos Métodos de Ensaio para Avaliação da Expansibilidade das Escórias de Aciaria. Dissertação (Mestrado) - Escola Politécnica da Universidade de São Paulo, São Paulo, 2000.

MARQUES, G. L. O.. Dimensionamento de Pavimentos: Método do DNER. In: Notas de Aula Disciplina Pavimentação TRN 032. Juiz Fora: Universidade Federal de Juiz Fora, 2009.

OLIVEIRA, T. M.. Caracterização de misturas de rejeitos de minério de ferro melhoradas com adição de cimento com vistas à aplicação em estradas e aterros. Dissertação (Mestrado em Geotecnia; Saneamento ambiental) Universidade Federal de Viçosa, Viçosa, 2013.

PARENTE, E. B.; BOAVISTA, A. H.; SOARES, J. B.. Estudo do comportamento mecânico de misturas de solo e escória de aciaria para aplicação na construção rodoviária na região metropolitana de Fortaleza. In: CONGRESSO DE PESQUISA E ENSINO EM TRANSPORTE DA ANPET, 29. Anais. Balneário Camboriú, 2015.

PINHEIRO NETO, J. C.; OLIVEIRA, F. H. L.; AGUIAR, M. F. P.. Revisão de estudos sobre a aplicação de escória de aciaria na pavimentação rodoviária. In: RAPV - REUNIÃO ANUAL DE PAVIMENTAÇÃO, 44; ENACOR - ENCONTRO NACIONAL DE CONSERVAÇÃO RODOVIÁRIA, 18. Anais. 2015.

PIRES, P. M.; TEIXEIRA, J. E. S. L.; NEPOMUCENO, D. V.; FURIERI, E. C.. Laboratory and field evaluation of KR slagstabilized soil for paving applications. Journal of Materials in Civil Engineering, v.31, n.9, 2019.

RODRIGUES, K. H. P.. Estudo de estabilização granulométrica de solos utilizando rejeito de mineração. Dissertação (Mestrado em Geotecnia) - Universidade Federal de Ouro Preto, Ouro Preto, 2018.

SANTOS, A. L.. Caracterização do comportamento mecânico de misturas de solo-escória de aciaria-cinza volante visando a aplicação em pavimentação. Dissertação (Mestrado em Tecnologias para o Desenvolvimento Sustentável) Universidade Federal de São João Del-Rei, Ouro Branco, 2013.

SANTOS, A. L.; PITANGA, H. N.; BERNAARDES-SILVA, A. C.; SILVA, T.. Caracterização do Comportamento Mecânico de Misturas de Solo-Escória de Aciaria-Cinza Volante Visando a Aplicação em Pavimentação. Revista Brasileira de Energias Renováveis, v.7, n.1, 2018. DOI: http://doi.org/10.5380/rber.v6i1.57963

A CBPC - Companhia Brasileira de Produção Científica (CNPJ: 11.221.422/0001-03) detém os direitos materiais desta publicação. Os direitos referem-se à publicação do trabalho em qualquer parte do mundo, incluindo os direitos às renovações, expansões e disseminações da contribuição, bem como outros direitos subsidiários. Todos os trabalhos publicados eletronicamente poderão posteriormente ser publicados em coletâneas impressas sob coordenação da Sustenere Publishing, da Companhia Brasileira de Produção Científica e seus parceiros autorizados. Os (as) autores (as) preservam os direitos autorais, mas não têm permissão para a publicação da contribuição em outro meio, impresso ou digital, em português ou em tradução. 